\title{
Graphene and Mobile Ions: The Key to All-Plastic, Solution-Processed Light- Emitting Devices
}

\author{
Piotr Matyba, ${ }^{\dagger, \|}$ Hisato Yamaguchi, ${ }^{\ddagger}, \|$ Goki Eda, ${ }^{\neq, \perp}$ Manish Chhowalla, ${ }^{\neq, \perp}$ Ludvig Edman, ${ }^{\dagger}$ and \\ Nathaniel D. Robinson ${ }^{\S . *}$ \\ ${ }^{\dagger}$ The Organic Photonics and Electronics Group, Department of Physics, Umeå University, SE-90187 Umeå, Sweden, ${ }^{\ddagger}$ Department of Materials Science and Engineering,

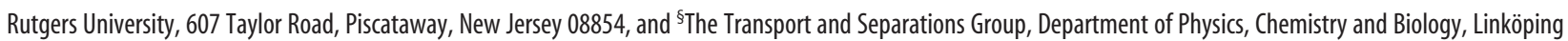 \\ University, SE-58183 Linköping, Sweden. ${ }^{\perp}$ Present address: Department of Materials, Imperial College London, London SW7 2AZ, UK. "These authors contributed \\ equally to this work.
}

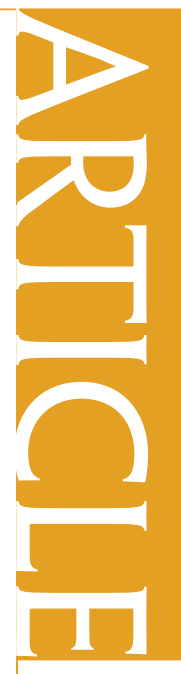

$\mathrm{T}$ he first OLEDs ${ }^{1-3}$ were a scientific breakthrough, as few expected carbon-based semiconductors to emit light under electrical stimulation as ultrapure inorganic semiconductors do. OLED devices based on light-emitting and semiconducting polymers ${ }^{4}$ (termed p-OLEDs) are particularly interesting from the perspective of low-cost fabrication using rollto-roll techniques since the polymeric active material can be processed from solution. The $\mathrm{p}$-OLED is typically built in a relatively simple structure with two charge-injecting electrodes sandwiching the light-emitting polymer. Holes are injected into the HOMO of the polymer from the positive anode, and electrons are injected into the LUMO of the polymer from the negative cathode. These holes and electrons recombine in the bulk of the polymer forming an exciton, which can decay and emit light. In order to inject the holes and electrons in an efficient and balanced manner, the work function of the anode and cathode must, to a first approximation, match the HOMO and LUMO of the light-emitting polymer, respectively.

The most commonly used anode material in p-OLEDs is ITO. When coated with a thin and planarizing layer of poly $(3,4-$ ethylenedioxythiophene) mixed with poly(styrenesulfonate) (PEDOT-PSS), ITO has an appropriate work function for hole injection and high conductivity and transparency; the latter is important so that the light generated within the active layer can escape the confines of the device. However, ITO is far from an ideal material from a life-cycle perspective because it should be handled carefully when recycled (as with many inorganic electronic materials), it must be trans-
ABSTRACT The emerging field of "organic" or "plastic" electronics has brought low-voltage, ultrathin, and energy-efficient lighting and displays to market as organic light-emitting diode (OLED) televisions and displays in cameras and mobile phones. Despite using carbon-based materials as the light-emitting layer, previous efficient organic electronic light-emitting devices have required at least one metal electrode. Here, we utilize chemically derived graphene for the transparent cathode in an all-plastic sandwich-structure device, similar to an OLED, called a light-emitting electrochemical cell (LEC). Using a screen-printable conducting polymer as a partially transparent anode and a micrometer-thick active layer solution-deposited from a blend of a light-emitting polymer and a polymer electrolyte, we demonstrate a light-emitting device based solely on solution-processable carbon-based materials. Our results demonstrate that low-voltage, inexpensive, and efficient light-emitting devices can be made without using metals. In other words, electronics can truly be "organic".

KEYWORDS: graphene · light-emitting device $\cdot$ polymer $\cdot$ light-emitting electrochemical cell · electroluminescence

ported over long distances, and the world's reserve of In is apparently being depleted. Accordingly, researchers have been searching for transparent, conducting alternatives to ITO for over 15 years. ${ }^{5}$

The situation regarding the cathode in p-OLEDs is even more challenging. The position of the LUMO of commonly employed light-emitting polymers dictates that the cathode must have a very low work function, which unfortunately is concomitant with poor stability under ambient conditions as such materials are prone to react with oxygen and moisture. Moreover, the deposition of such low work-function cathode materials in p-OLEDs (e.g., Ca or $\mathrm{Ba}$ ) is not amenable to solution processing, which has prohibited the realization of a solely solution-processed OLED device.

Recently, an exciting carbon-based material called graphene was "discovered". 6 Besides its fascinating electron transport properties, ${ }^{7}$ graphene can be solution-

\section{*Address correspondence to natro@ifm.liu.se.}

Received for review December 18, 2009 and accepted January 18, 2010.

Published online February 4, 2010. $10.1021 / \mathrm{nn} 9018569$

() 2010 American Chemical Society 


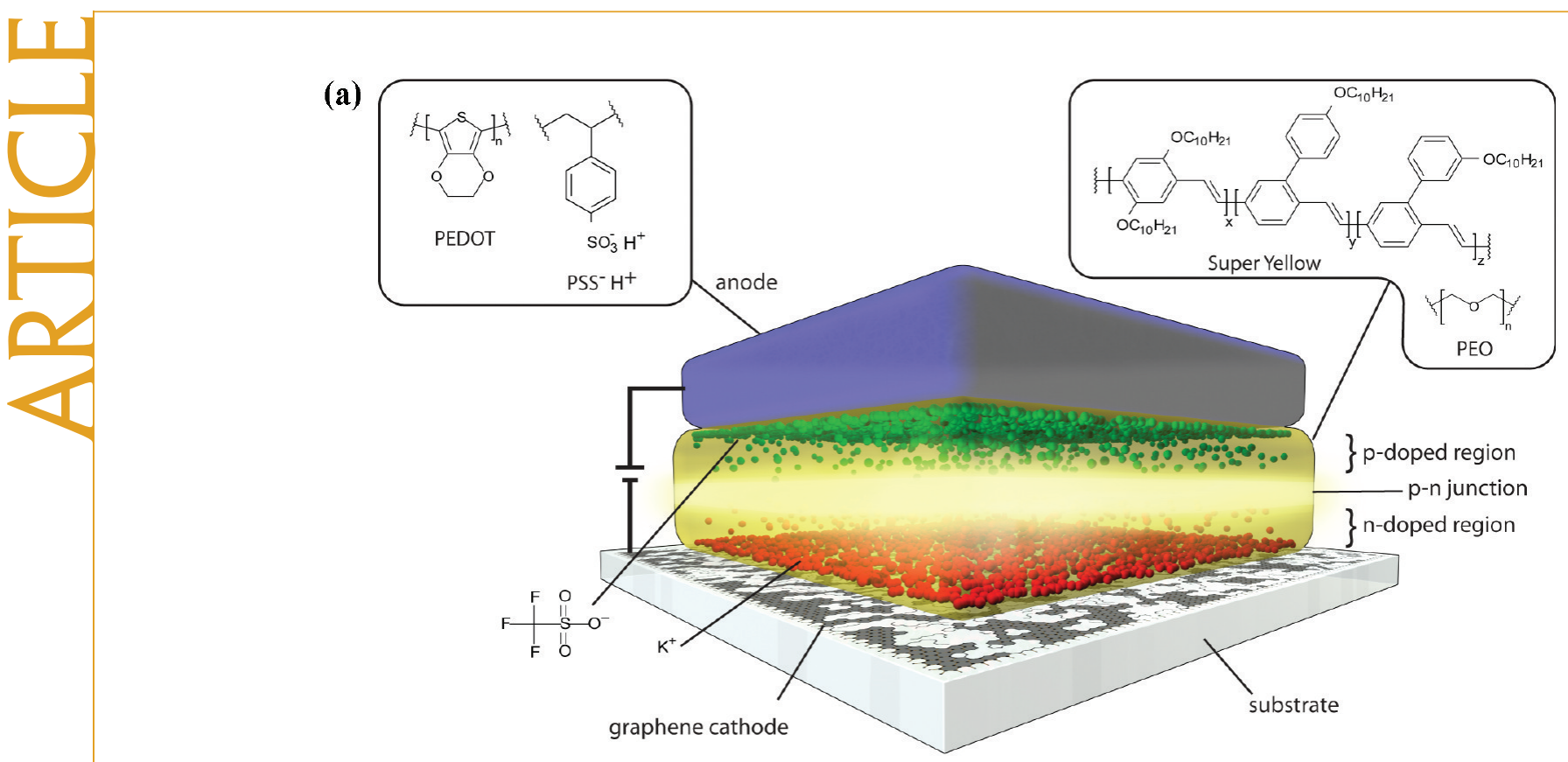

(b)

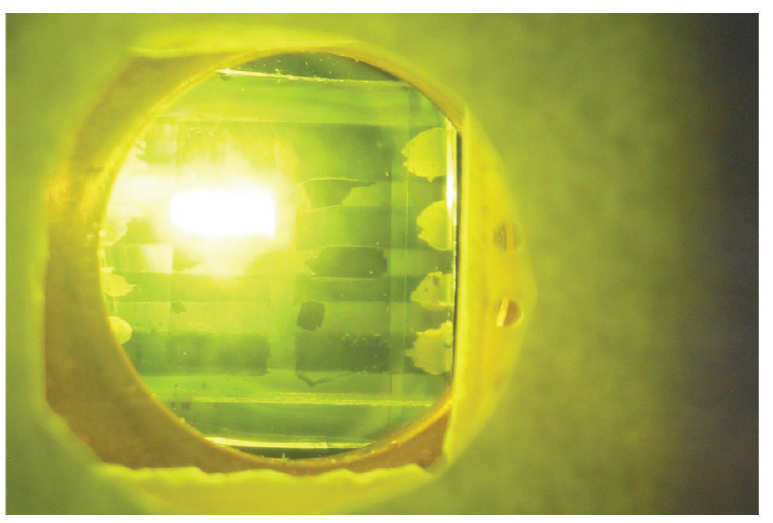

(c)

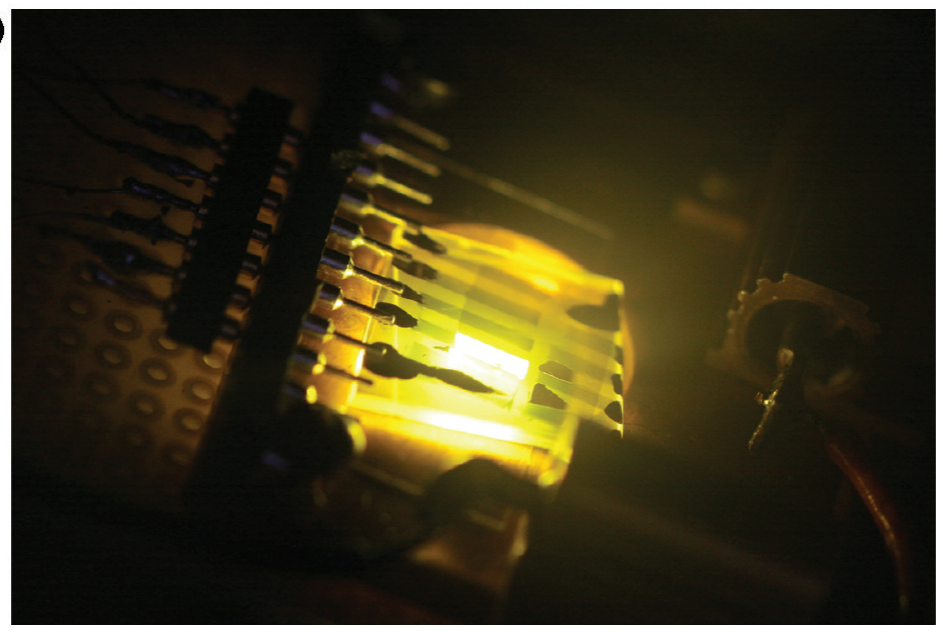

Figure 1. All-plastic, solution-processed LECs. (a) Schematic illustrating the structure and operation of the device. During operation, light is emitted both upward, through the PEDOT-PSS electrode, and downward, through the graphene electrode. (b) Photograph of an LEC during light emission, as viewed through the graphene cathode. (c) Similar photograph, as viewed through the PEDOT-PSS anode. Photo courtesy of the authors.

processable, highly conductive, and nearly transparent. ${ }^{8-11}$ When oxidized and exfoliated from graphite, graphene oxide can be suspended in water, coated onto a surface, and then chemically reduced. ${ }^{12}$
Upon thermal annealing, the chemically derived graphene (CDG) forms a conductive, transparent film suitable for use as the electrode in opto-electronic components. However, considering the high work function 
of CDG, reported to be between 4.2 and $4.6 \mathrm{eV}$ depending on the chemical composition, ${ }^{13}$ it is unreasonable to expect that it will be a viable cathode material in p-OLED applications.

Here, we have employed a frequently overlooked alternative to the OLED: the light-emitting electrochemical cell (LEC). ${ }^{14}$ It is similar to a p-OLED in structure, but in LEC devices the light-emitting polymer (or smallmolecule compound) is blended with an electrolyte. The mobile ions in the electrolyte rearrange when a potential is applied between the electrodes, forming high charge-density layers at each electrode interface, allowing efficient and balanced injection of electrons and holes into the polymer. ${ }^{15}$ It is particularly noteworthy that efficient injection is possible regardless of the work function of the electrodes, as exemplified by the use of stable materials (such as gold) for both the cathode and anode in LEC devices. ${ }^{16,17}$ Unfortunately, electrochemical side reactions, involving, for example, the electrode materials, can cause problems. ${ }^{18,19}$ Recent LEC devices have demonstrated distinct improvements in performance, both from an operational lifetime and from an efficiency perspective..$^{20-23}$ However, the LEC devices reported to date have invariably relied on at least one metal-based electrode.

Here, we report an LEC made entirely of organic materials (i.e., without any metal electrode) and in which all of the components (cathode, anode, and active material) are solution-processable. We used CDG as the cathode and a commercially available PEDOT-PSS "ink" (designed for screen printing) as the anode. The active layer contained a blend of a poly(para-phenylene vinylene) copolymer called "Super Yellow" (SY) and an electrolyte in the form of the salt $\mathrm{KCF}_{3} \mathrm{SO}_{3}$ dissolved in poly(ethylene oxide) (PEO). A schematic of the device structure and operation is presented in Figure 1a. The ions in the active layer facilitate not only efficient and balanced injection but also electrochemical doping of the semiconducting polymer. ${ }^{14-16,24}$ The $p$ - and $\mathrm{n}$-doped regions extend from the anode and cathode, respectively, growing until a light-emitting $p-n$ junction is formed (see Figure 1a). As a result, the thickness of the active layer in an LEC has a marginal impact on the device's performance, in sharp contrast to the case of an OLED. This has clear advantages when solution processing the films, as coating and printing pin-holefree films around $100 \mathrm{~nm}$ thick (as is required in p-OLEDs) over large surfaces has proven to be very challenging. The LEC devices presented in this paper all have active layers between 1 and $2 \mu \mathrm{m}$ thick. Two photographs of operating "thick" devices, as viewed through the graphene cathode and PEDOT-PSS anode are presented in Figure 1b,c, respectively.

Figure 2 a presents the current density and the brightness (measured from the graphene cathode side) for a PEDOT-PSS/\{SY + PEO $\left.+\mathrm{KCF}_{3} \mathrm{SO}_{3}\right\} /$ graphene device as a function of applied voltage, recorded with a scan (a)
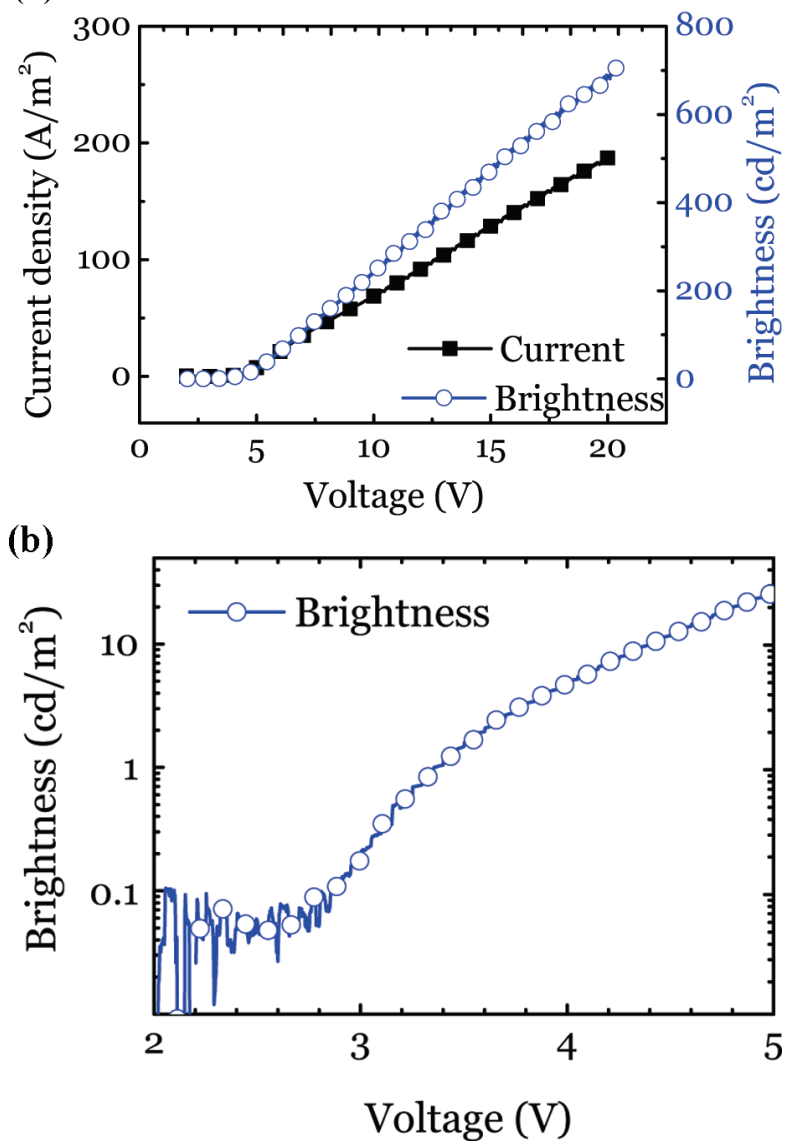

Figure 2. Optoelectronic performance of a carbon-based, metalfree LEC. Current density (solid black squares) and brightness (open blue circles) as a function of voltage for a PEDOT-PSS/ $\left\{\mathrm{SY}+\mathrm{PEO}+\mathrm{KCF}_{3} \mathrm{SO}_{3}\right\} /$ graphene device, recorded at a scan rate of $0.01 \mathrm{~V} / \mathrm{s}$. (a) Brightness as a function of voltage in linear scale. (b) shows the same plot as (a) but in logarithmic scale near the turn-on voltage.

rate of $0.01 \mathrm{~V} / \mathrm{s}$. Figure $2 \mathrm{~b}$ shows the brightness data in better detail at low voltages, which reveals that the device begins to emit light at a voltage $V_{\text {turn-on }}=2.8 \mathrm{~V}$. This is notably close to the band gap potential of $S Y^{25}$ $V_{\mathrm{BG}}=E_{\mathrm{g}} / e \approx 2.4-2.5 \mathrm{~V}$, particularly considering the modest conductivity of the solution-processed graphene cathode (sheet resistivity $\approx 5 \mathrm{k} \Omega$ /square, compared to, e.g., approximately $20 \Omega$ /square for a typical ITO electrode) and the generous thickness of the active layer.

Since each electrode in this device is at least partially transparent, light is emitted in "all" directions, that is, through both the graphene cathode and the PEDOT-PSS anode. This is clearly demonstrated in the photograph in Figure 3a, where an operating device in a dark room illuminates two white sheets of paper, positioned on opposite sides of the device. The light emitted from each side is similar in intensity, as demonstrated in the graphs provided in Figure 3b,c, which present the current density and brightness as a function of voltage for two PEDOT-PSS/ $\left\{\mathrm{SY}+\mathrm{PEO}+\mathrm{KCF}_{3} \mathrm{SO}_{3}\right\} /$ graphene devices recorded at a scan rate of $0.1 \mathrm{~V} / \mathrm{s}$ from 

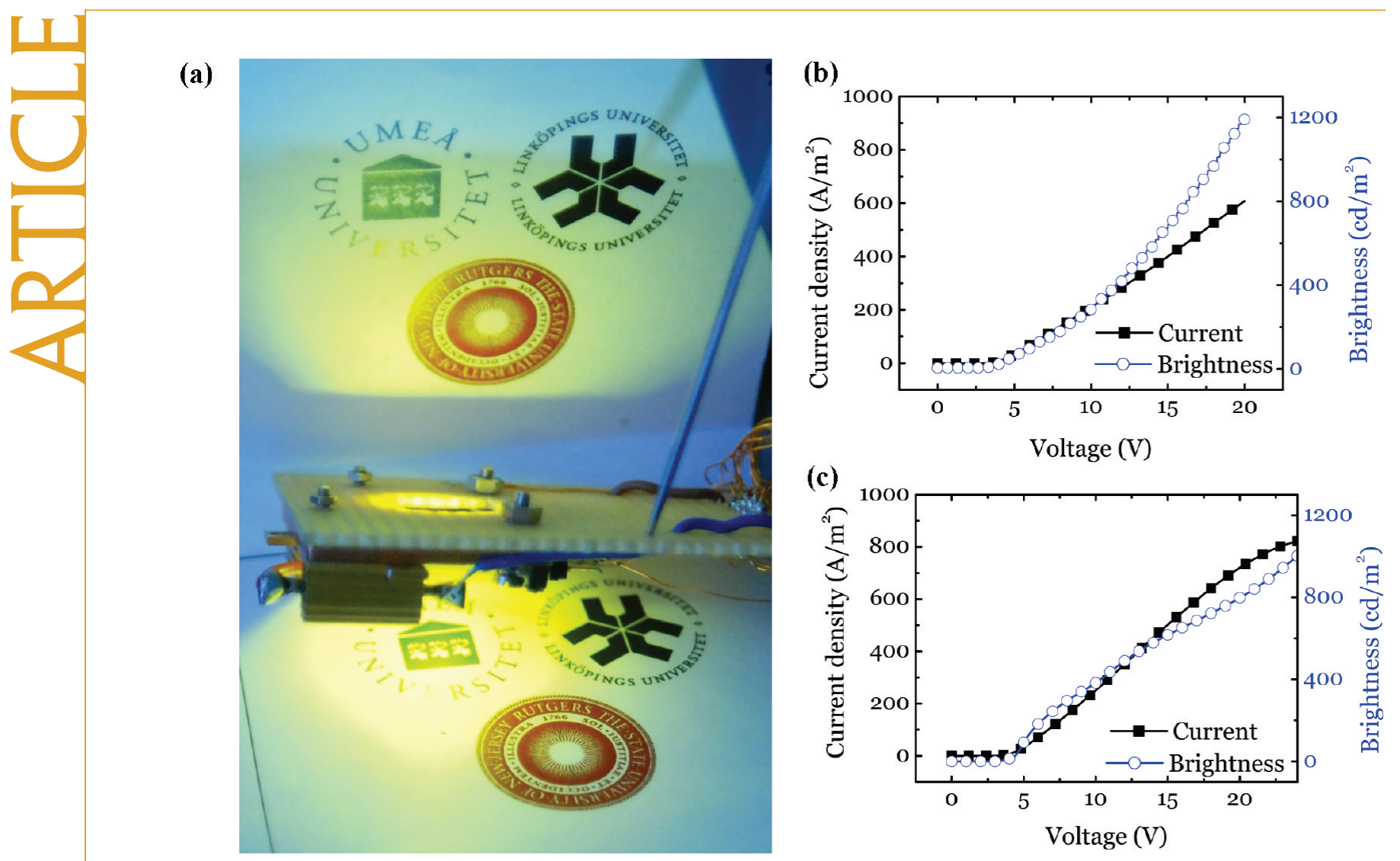

(c)

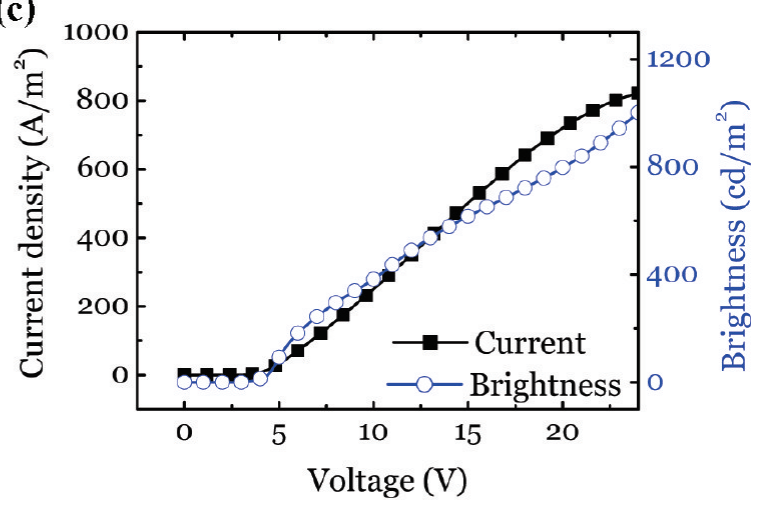

Figure 3. Omni-directional light emission from a carbon-based, metal-free LEC. (a) Photograph of the two-sided emission from the sandwich device. The edge of the light-emitting device is visible in the specially designed holder. Light coming through the PEDOTPSS anode illuminates a sheet of paper above the device, while the light visible from the lower side of the device has passed through the graphene cathode. (b) Current density and brightness, measured through the graphene cathode, versus applied potential swept at $0.1 \mathrm{~V} / \mathrm{s}$. (c) Current density and brightness, measured through the PEDOT-PSS anode at the same sweep rate. University logos used with permission from Linköping University, Umeå University, and Rutgers University.

the graphene cathode side and the PEDOT-PSS anode side, respectively.

Considering the light emitted from both sides of the device, we calculate the quantum efficiency and the power conversion efficiency to be $9 \mathrm{~cd} / \mathrm{A}$ and 5 $\mathrm{Im} / \mathrm{W}$, respectively, at $V=4 \mathrm{~V}$ for the device depicted in Figure 2. These are rather impressive values, close to the state-of-the-art for conjugated polymer LEC devices. ${ }^{20,22,26,27}$ Still, we believe there is considerable room for improvement of both the chemistry of the devices and our fabrication process.

We have also tested an LEC with a graphene anode and an aluminum cathode (see the Supporting Information) and find that graphene also works as an anode. This means, in principle, that graphene could be used as both electrodes in the LEC. We used PEDOT-PSS for the top electrode in the devices described above because it was easier to coat and pattern PEDOT-PSS than to laminate a second graphene electrode to a device. The fact that graphene functions both as an anode and a cathode in electrochemical devices, such as LECs, reflects the breadth of its electrochemical stability window and distinguishes graphene from, for example, PEDOT-PSS and ITO. PEDOT-PSS only works well as an anode because it is reduced to an undoped, dark blue, and poorly conducting redox state when operated as a cathode. Similarly, ITO tends to turn brownish with concomitant degradation in the electrical conductivity when biased as the negative cathode in an electrochemical device.

To test the use of graphene as a transparent anode in a p-OLED, we fabricated devices by coating a thin layer of SY (thickness $\approx 70 \mathrm{~nm}$ ) on top of a graphene anode and completed the stack with a Ca cathode. Even though the p-OLED devices were not optimized and suffered from a relatively high leakage current (presumably due to microshorts caused by the relatively rough surface of the graphene anode), the reasonable device performance $\left(V_{\text {turn-on }}=7 \mathrm{~V},>200 \mathrm{~cd} / \mathrm{m}^{2}\right.$ and $1.5 \mathrm{~cd} / \mathrm{A}$ at $V=23 \mathrm{~V}$ ) confirms that graphene can be a viable lowcost replacement for ITO as the transparent anode in OLEDs. Better results have recently been reported by Wu et al. ${ }^{28}$

To summarize, we demonstrated an efficient solid-state, metal-free, and solution-processed electroluminescent LEC with a graphene cathode and PEDOT-PSS anode. We point out that the broad electrochemical stability of graphene and the work function independence of the LEC are both necessary to make this possible. This demonstration that light- 
emitting devices can make the leap to ubiquitous applications like consumer packaging seems timely now that prior progress in the field of organic elec- tronics is commercially available. After more than 20 years since their discovery, truly plastic electronics have finally arrived.

\section{METHODS}

Graphite powders (Branwell Graphite Ltd.) with size $>425$ $\mu \mathrm{m}$ were exfoliated via a modified Hummer's method. ${ }^{29}$ After repeated rinsing with acid used for the exfoliation, unexfoliated graphite particles were removed by mild centrifugation. The graphene oxide (GO) suspension (in water) was then diluted and vacuum-filtered onto cellulose paper filters. ${ }^{11}$ The GO films were deposited onto rigid (quartz) substrates and reduced in an $\mathrm{Ar} / \mathrm{H}_{2}$ environment $\left(\mathrm{Ar} / \mathrm{H}_{2} 90: 10\right)$ by annealing at $1000^{\circ} \mathrm{C}$ for $15 \mathrm{~min}$. The films were preannealed at $200{ }^{\circ} \mathrm{C}$ in vacuum overnight to minimize the possible loss of carbon atoms upon annealing. The resulting graphene electrodes had a sheet resistivity of approximately $5 \mathrm{k} \Omega / \mathrm{square}$.

The commercially available conjugated polymer, known as "Super Yellow" (Merck catalogue number PDY-132), polyethylene oxide $\left(M_{\mathrm{w}}=5 \times 10^{6} \mathrm{~g} / \mathrm{mol}\right.$, Aldrich), and $\mathrm{KCF}_{3} \mathrm{SO}_{3}$ (Alfa Aesar, purity $98 \%$ ) were each dissolved in cyclohexanone (Aldrich, purity $99.8 \%$ ) at a concentration of $5 \mathrm{mg} / \mathrm{mL}$ each. These three master solutions were mixed together in a volume ratio of SY/ $\mathrm{PEO} / \mathrm{KCF}_{3} \mathrm{SO}_{3}=1.0: 1.35: 0.25$ to form a thick solution used for the active layer in the LECs. The solution was drop-cast onto each 1 $\times 1 \mathrm{~cm}^{2}$ graphene substrate and dried on a hot plate at $T=360$ $\mathrm{K}$ for $12 \mathrm{~h}$. The resulting thickness of the active layer was $1-2$ $\mu \mathrm{m}$. A mask was created by establishing a mesh pattern (individual electrodes approximately $5 \times 1 \mathrm{~mm}^{2}$ each) in a thin cellophane mask. The mask was placed on the active material and attached to the edges of the substrate, and the entire mask and substrate assembly was heated at $T=360 \mathrm{~K}$ for $\geq 10 \mathrm{~min}$. The PEDOT-PSS blend (Clevios S V3, H.C. Starck) was spread on top of the device using the edge of a glass microscope slide, which rested on the mask. The mask was removed, and the device again baked on a hot plate at $T=390 \mathrm{~K}$ for at least $12 \mathrm{~h}$. We estimate the thickness of the PEDOT-PSS top electrodes to be 5-10 $\mu \mathrm{m}$. Finally, a Ag/AgCl paste was added to the edge of the PEDOT-PSS and graphene electrodes to facilitate electronic contact with the source meter. The entire device was placed in a specially designed sample holder (parts of which are visible in Figures $1 \mathrm{~b}, \mathrm{c}$ and $3 \mathrm{a}$ ) that contacted the $\mathrm{Ag} / \mathrm{AgCl}$ pads and allowed each $5 \times 1 \mathrm{~mm}^{2}$ "pixel" to be addressed and measured individually.

The $\mathrm{p}$-OLED device was fabricated by spin coating a graphene anode with the SY master solution, resulting in a SY layer approximately $70 \mathrm{~nm}$ thick. A Ca cathode was then thermally evaporated on top of the device (thickness $50 \mathrm{~nm}$ ) through a shadow mask. The Ca layer was thereafter capped with a thin $(50 \mathrm{~nm})$ layer of Al thermally evaporated through the same mask and inside the same evaporation chamber.

The devices were driven by, and current measured with, a Keithley 2400 source meter. The brightness was measured using a calibrated photodiode with an eye response filter (Hamamatsu Photonics, S9219-01) connected through a currentto-voltage amplifier to a HP 34401A meter. All device fabrication and characterization were performed in two interconnected $\mathrm{N}_{2}$-filled gloveboxes with $<1$ ppm $\mathrm{H}_{2} \mathrm{O}$ and $<1 \mathrm{ppm} \mathrm{O}_{2}$.

Acknowledgment. N.D.R. thanks the Swedish Research Council (Vetenskapsrådet) for financial support. L.E. is a "Royal Swedish Academy of Sciences Research Fellow" supported by a grant from the Knut and Alice Wallenberg Foundation. L.E. and P.M. also thank the Swedish Research Council (Vetenskapsrådet) for financial support. G.E., H.Y., and M.C. acknowledge funding from the National Science Foundation CAREER Award (ECS 0543867). M.C. acknowledges funding from the Donald H. Jacobs Chair. G.E. would like to acknowledge funding from the Royal Society International Fellowship. M.C. would like to thank support from the Royal Society's Wolfson Merit Award. M.C. and G.E. also acknowledge support from the Centre for Advanced Structural Ceramics (CASC) at Imperial. The 3-D graphic presented in Figures 1a was commissioned from www.planet11.com. Correspondence regarding LEC devices can be sent to N.D.R. (natro@ifm.liu.se) and L.E. (ludvig.edman@physics.umu.se).

Correspondence regarding the graphene film preparation, or requests for graphene material samples, should be sent to M.C. (m.chhowalla@imperial.ac.uk).

Supporting Information Available: A second image of the LEC device under operation, optoelectronic measurements from a graphene/ $\left\{\mathrm{SY}+\mathrm{PEO}+\mathrm{KCF}_{3} \mathrm{SO}_{3}\right\} / \mathrm{Al} \mathrm{LEC}$, and a brief discussion of using flexible substrates with graphene electrodes. This material is available free of charge via the Internet at http://pubs.acs.org.

\section{REFERENCES AND NOTES}

1. Burroughes, J. H.; Bradley, D. D. C.; Brown, A. R.; Marks, R. N.; Mackay, K.; Friend, R. H.; Burns, P. L.; Holmes, A. B. Light-Emitting-Diodes Based on Conjugated Polymers. Nature 1990, 347, 539-541.

2. Braun, D.; Heeger, A. J. Visible-Light Emission from Semiconducting Polymer Diodes. Appl. Phys. Lett. 1991, 58, 1982-1984.

3. Tang, C. W.; Vanslyke, S. A. Organic Electroluminescent Diodes. Appl. Phys. Lett. 1987, 51, 913-915.

4. Friend, R. H.; Gymer, R. W.; Holmes, A. B.; Burroughes, J. H.; Marks, R. N.; Taliani, C.; Bradley, D. D. C.; Dos Santos, D. A.; Bredas, J. L.; Logdlund, M.; Salaneck, W. R. Electroluminescence in Conjugated Polymers. Nature 1999, 397, 121-128.

5. Gustafsson, G.; Cao, Y.; Treacy, G. M.; Klavetter, F.; Colaneri, N.; Heeger, A. J. Flexible Light-Emitting-Diodes Made from Soluble Conducting Polymers. Nature 1992, 357, 477-479.

6. Novoselov, K. S.; Geim, A. K.; Morozov, S. V.; Jiang, D.; Zhang, Y.; Dubonos, S. V.; Grigorieva, I. V.; Firsov, A. A. Electric Field Effect in Atomically Thin Carbon Films. Science 2004, 306, 666-669.

7. Geim, A. K. Graphene: Status and Prospects. Science 2009, 324, 1530-1534.

8. Wang, X.; Zhi, L. J.; Mullen, K. Transparent, Conductive Graphene Electrodes for Dye-Sensitized Solar Cells. Nano Lett. 2008, 8, 323-327.

9. Becerril, H. A.; Mao, J.; Liu, Z.; Stoltenberg, R. M.; Bao, Z.; Chen, Y. Evaluation of Solution-Processed Reduced Graphene Oxide Films as Transparent Conductors. ACS Nano 2008, 2, 463-470.

10. Cai, W. W.; Zhu, Y. W.; Li, X. S.; Piner, R. D.; Ruoff, R. S. Large Area Few-Layer Graphene/Graphite Films as Transparent Thin Conducting Electrodes. Appl. Phys. Lett. 2009, 95, 123115.

11. Eda, G.; Fanchini, G.; Chhowalla, M. Large-Area Ultrathin Films of Reduced Graphene Oxide as a Transparent and Flexible Electronic Material. Nat. Nanotechnol. 2008, 3, 270-274.

12. Mattevi, C.; Eda, G.; Agnoli, S.; Miller, S.; Mkhoyan, K. A.; Celik, O.; Mostrogiovanni, D.; Granozzi, G.; Garfunkel, E.; Chhowalla, M. Evolution of Electrical, Chemical, and Structural Properties of Transparent and Conducting Chemically Derived Graphene Thin Films. Adv. Funct. Mater. 2009, 19, 2577-2583.

13. Shin, H. J.; Kim, K. K.; Benayad, A.; Yoon, S. M.; Park, H. K.; Jung, I. S.; Jin, M. H.; Jeong, H. K.; Kim, J. M.; Choi, J. Y.; Lee, Y. H. Efficient Reduction of Graphite Oxide by Sodium Borohydride and Its Effect on Electrical Conductance. Adv. Funct. Mater. 2009, 19, 1987-1992.

14. Pei, Q. B.; Yu, G.; Zhang, C.; Yang, Y.; Heeger, A. J. Polymer Light-Emitting Electrochemical Cells. Science 1995, 269 1086-1088. 

Emitting Electrochemical Cells. Nat. Mater. 2008, 7, 167.

16. Robinson, N. D.; Shin, J. H.; Berggren, M.; Edman, L. Doping Front Propagation in Light-Emitting Electrochemical Cells. Phys. Rev. B 2006, 74, 155210.

17. Alem, S.; Gao, J. The Effect of Annealing/Quenching on the Performance of Polymer Light-Emitting Electrochemical Cells. Org. Electron. 2008, 9, 347-354.

18. Fang, J.; Matyba, P.; Robinson, N. D.; Edman, L. Identifying and Alleviating Electrochemical Side-Reactions in LightEmitting Electrochemical Cells. J. Am. Chem. Soc. 2008, $130,4562-4568$.

19. Matyba, P.; Andersson, M. R.; Edman, L. On the Desired Properties of a Conjugated Polymer-Electrolyte Blend in a Light-Emitting Electrochemical Cell. Org. Electron. 2008, 9, 699-710.

20. Fang, J. F.; Matyba, P.; Edman, L. The Design and Realization of Flexible, Long-Lived Light-Emitting Electrochemical Cells. Adv. Funct. Mater. 2009, 19, 2671-2676.

21. Graber, S.; Doyle, K.; Neuburger, M.; Housecroft, C. E.; Constable, E. C.; Costa, R. D.; Orti, E.; Repetto, D.; Bolink, H. J. A Supramolecularly-Caged Ionic Iridium(III) Complex Yielding Bright and Very Stable Solid-State Light-Emitting Electrochemical Cells. J. Am. Chem. Soc. 2008, 130, 14944-14945.

22. Shao, Y.; Bazan, G. C.; Heeger, A. J. Long-Lifetime Polymer Light-Emitting Electrochemical Cells. Adv. Mater. 2007, 19, $365-370$.

23. Slinker, J. D.; Rivnay, J.; Moskowitz, J. S.; Parker, J. B.; Bernhard, S.; Abruna, H. D.; Malliaras, G. G. Electroluminescent Devices from lonic Transition Metal Complexes. J. Mater. Chem. 2007, 17, 2976-2988.

24. Matyba, P.; Maturova, K.; Kemerink, M.; Robinson, N. D.; Edman, L. The Dynamic Organic $\mathrm{p}-\mathrm{n}$ Junction. Nat. Mater. 2009, 8, 672-676.

25. Edman, L.; Moses, D.; Heeger, A. J. Influence of the Anion on the Kinetics and Stability of a Light-Emitting Electrochemical Cell. Synth. Met. 2003, 138, 441-446.

26. Yang, Y.; Pei, Q. B. Efficient Blue-Green and White LightEmitting Electrochemical Cells Based on Poly-9,9-bis(3,6dioxaheptyl)-fluorene-2,7-diyl. J. Appl. Phys. 1997, 81, 3294-3298.

27. Yu, Z. B.; Sun, M. L.; Pei, Q. B. Electrochemical Formation of Stable $\mathrm{p}-\mathrm{i}-\mathrm{n}$ Junction in Conjugated Polymer Thin Films. J. Phys. Chem. B 2009, 113, 8481-8486.

28. Wu, J.; Agrawal, M.; Becerril, H. A.; Bao, Z.; Liu, Z.; Chen, Y.; Peumans, P. Organic Light-Emitting Diodes on SolutionProcessed Graphene Transparent Electrodes. ACS Nano 2010, 4, 43-48.

29. Hirata, M.; Gotou, T.; Horiuchi, S.; Fujiwara, M.; Ohba, M. Thin-Film Particles of Graphite Oxide 1: High-Yield Synthesis and Flexibility of the Particles. Carbon 2004, 42, 2929-2937. 